\title{
Teaching Ideas for Improving Oral Performance through Formulaic Language Instruction
}

\author{
Chie Ogawa \\ Kyoto Sangyo University
}

\begin{abstract}
This article suggests three teaching ideas to help L2 learners improve speaking performances through form-focused instruction using formulaic language. Formulaic language is considered an effective way to foster speaking fluency because prefabricated chunks are faster to retrieve than constructing sentences word by word (Wray, 2002). In spite of the benefits of learning formulaic language in L2 learning theory, few empirical studies were found which examined the effects of formulaic language instruction in intact classrooms, in particular in the EFL (English as a Foreign Language) context. By introducing some effective classroom tasks to foster L2 learners' speaking fluency focusing on formulaic language in this article, the author emphasizes the need for empirical research involving EFL learners.
\end{abstract}

Key words: Speaking, Formulaic Language, Automatization, Proceduralization, Focus on Form, Fluency, CALF, Instructed SLA

\section{Introduction}

According to Wray (2008), formulaic language refers to large units of processing, in other words, lexical units that are more than one word long. She explains formulaic language as sequences of words that are in some regard not entirely predictable, a function that is only achieved with the whole expression or features of structure such as morphology or word order that are non-canonical by acknowledging that it is not easy to have consensus across domains (Wray, 2013, p. 317). The words in a formulaic sequence are glued together and stored as a single big word (Ellis, 1996).

The study of formulaic language is related to automaticity, and it also plays an important role in second language acquisition. Learners' automatic access to prefabricated chunks, which are stored in memory, can lead to fluency development (Boers \& Lindstromberg, 2012; Segalowitz, 2003; Wood, 2009, 2015) through the repeated use of formulaic language. Linguistic chunks can become part of production rules and can be retrieved directly from declarative memory without the need for computations in working memory (Wood, 2010, p. 3). If learners process formulaic language automatically, they can use more attentional resources for other areas.

According to Boers, Eyckmans, Kappel, Stengers, and Demecheleer (2006), there are three reasons why acquiring formulaic language is believed to be 
beneficial to L2 learners. First, the mastery of the idiomatic aspects of natural language can help learners sound more native-like. Second, the mastery of formulaic language can help learners to speak more fluently because prefabricated sequences or ready-made chunks can be retrieved faster than sentences generated word by word under real-time conditions. Third, formulaic language can help learners produce more accurate language provided that the prefabricated chunks are stored correctly in memory.

Wray (2000) acknowledges the difficulty of mastering formulaic language for L2 learners because of the following reasons. The first reason is that L2 learners may not be exposed enough to the formulaic language. Formulaic language is often omitted in the interaction with L2 speakers although formulaic language is common for native speakers. The second reason is that formulaic language may not be taught very well. It seems difficult to match to the real-world experience of language in the classroom.

Gatbonton and Segalowitz's (1988) article has a significant contribution to practical classroom L2 teaching of automatization of formulaic language. They claimed that traditional repetition of the target form in a monotonous drill is not sufficient to acquire the target language because it lacks communicative context. Their suggestions demonstrate ways of incorporating repetition and rehearsals of useful formulaic language into a genuinely communicative task. They call this type of process creative automatization because students themselves generate and create appropriate utterances based on their understanding of the communicative situation. Automatizing utterances requires students to repeat utterances that would occur naturally in a normal communicative situation. Communication tasks can promote automatization of the target phrases within a communicative framework in the classroom. Gatbonton and Segalowiz suggest that the tasks should be designed for L2 learners to elicit short and memorizable utterances. The formulaic language should be multisituational so that it can be usable in many situations with little or no modification. By doing so, the short and memorizable formulaic language can help automatization take place within a short period of time. Rehearsal promotes fluency and familiarity with formulaic expression.

According to Boers and Lindstromberg (2012), ways to foster the use of greater breadth of formulaic sequences have been examined in many intervention studies, but few researchers have examined the proceduralization of formulaic sequences. In the following section, the author suggests form-focused instruction and demonstrates some types of tasks which can promote proceduralization of target formulaic language.

\section{Focus on Form}

\subsection{Text Enhancement and Pre-Task Planning}

Ellis (2016) explained four ways to incorporate focus on form into taskbased language teaching: text enhancement, corrective feedback (CF), pre-task planning, and task repetition. 
In text enhancement, linguistic features are underlined, bolded, or italicized so that learners could notice the target linguistic feature through typographical enhancement. There was a high probability that the participants noticed the target linguistic forms, as their salience was increased by the underlining (see Doughty, 1991; Lee \& Huang, 2008; Sharwood-Smith, 1993 for studies concerning the effectiveness of typographical cues such as underlining, bolding, and italicization).

Lee and Huang (2008) examined 20 text-enhancement studies in their meta-analysis and concluded that text enhancement has an overall positive effect, but the effect size is quite small. Lower proficiency learners may struggle to engage in processing both comprehending the meaning of the text and consciously attending to linguistic forms (Ogawa, 2019). Even if learners notice the target form, they may not acquire it and it might fail to be passed into long-term memory; therefore, Ellis (2016) recognized the importance of combining text enhancement with other instructional techniques that encourage intentional learning.

\subsection{Peer Feedback}

As one of the form-focused instruction methods, CF is considered effective in promoting noticing and is thus conducive to L2 learning (Lyster \& Saito, 2010; Mackey \& Goo, 2007; Russell \& Spada, 2006; Sato, 2017). Compared to teacher $\mathrm{CF}$, peer corrective feedback (PCF) might be considered as less effective because many L2 learners might not feel confident enough to provide $\mathrm{CF}$ or they may trust teacher CF but not PCF. However, research has shown that PCF has positive effects on L2 learners' language development (Kim, 2013; Sippel \& Jackson, 2015). The main difference between teacher $\mathrm{CF}$ and PCF is that L2 learners can act as a feedback receiver and provider. In other words, PCF serves two beneficial functions (Sato, 2017). From a feedback provider's point of view, a learner first needs to detect an error in the input which her peer produces. In order to do so, a provider must notice the gap between the error and the target-like production. This gives an opportunity to compare the peer's error and her own interlanguage and notice that she might make the same error and correct it internally. This cognitive process may contribute to restructuring of the feedback provider's L2 knowledge (Sato, 2017). On the other hand, from a receiver's point of view, PCF given by her peer may trigger noticing and push the speaker to modify the original utterance.

Although that the effects of PCF are theoretically and empirically acknowledged, L2 learners still might find it difficult to correct their classmates' errors due to the social and psychological nature of PCF. Philp, Walter, and Basturkmen (2010) explained that L2 learners hesitate to provide PCF because they feel less confident of their proficiency (e.g., readiness to correct as a learner) and social relationship (e.g., face saving). Related to this issue, Sato (2017) also suggests that it is essential for L2 learners to be trained how to interact with each other and how to provide $\mathrm{CF}$ to each other because providing CF to their peers is influenced by learners' social dynamics between peers. Therefore, teachers' role is important to create learners' mindset which is positive toward PCF so that they can avoid underscoring peer feedback and help L2 development. 
Yet, few studies, to my knowledge, have been carried out to explore the role of peer feedback on a speaking task, especially on the usage of the formulaic language. It is uncertain if and how the L2 learners are able to contribute to peer feedback and on their usage of the target linguistic features. Experimental studies of pedagogical interventions are much needed.

\subsection{Task Repetition}

Another important way to help L2 learners proceduralize and automatize the target formulaic language is through repetitive practices. However, merely repeating the same rules has been criticized because it does not provide a meaningful context in which students genuinely need to communicate. Automaticity is best achieved by the repeated use of language rules in a context of authentic communication (DeKeyser, 2003; De Ridder, Vangehuchten, \& Gómez, 2007; Segalowitz, 2003).

Task repetition is helpful for developing fluency because repetition allows learners to activate concepts and linguistic forms so that they are more easily and quickly accessed. Based on the limited attentional model of speech production (Skehan, 1998), low-proficient L2 learners face a number of challenges in the speaking process from conceptualization to articulation in Levelt's speech model (see Levelt, 1989) because demands of thinking of preverbal message and how to formulate the message efficiently are not yet efficiently processed. Repetition might reduce the attentional demands on learners to conceptualize, encode, and monitor their messages simultaneously.

One effective activity is the 4/3/2 task (e.g., Boers, 2014; Nation, 1989; Nation \& Newton, 2009; Thai \& Boers, 2016). In the 4/3/2 task, students talk about the same topic for 4 minutes, then 3 minutes, and finally 2 minutes. When the students talk about the same topic three times with increasing time pressure to perform more quickly, they must speak faster. Therefore, this task can be used in language classrooms to foster speaking fluency.

According to Nation (1989), the 4/3/2 task has three important features: repetition, reducing time, and a change of audience. These features directly affect fluency by encouraging L2 speakers to focus on the meaning under a time constraint. Nation's suggestions and rational were empirically proven by previous researchers (e.g., De Jong \& Perfetti, 2011; Thai \& Boers, 2016). Repeating the same topic helped L2 learners improve fluency more than the group who did not repeat the same topic (De Jong \& Perfetti, 2011). Shrinking time condition (4-3-2) was able to promote more fluency than having the constant time condition (3-3-3) (Boers, 2014; Thai \& Boers, 2016).

\section{Suggestions for Future Studies}

Considering many researchers have suggested form-focused instructions, few studies have examined the effects of form-focused instruction with formulaic language. For example, Wood (2009) conducted a case study of the classroom teaching of formulaic language and fluency development with a female 
Japanese learner of English. This study took place in an intensive study abroad class but only the female participant's speaking progress was analyzed. The fluency workshop consisted of 9 hours of instruction over 6 weeks. The sessions included an (1) input stage, (2) automatization stage, (3) practice and production stage, and (4) free talk stage. In the input stage, the student listened to native English speakers' personal stories. In the automatization stage, the learners shadowed the recording with a focus on the formulaic language and also did a dictogloss, which includes texts rich in formulaic language. In the practice and production stage, the student did the 4/3/2 task, in which she told personal narratives. In the free talk stage, students in small groups took turns listening to individuals speaking spontaneously about the topics they had been assigned.

The female participant did a monologue narrative recording before she started the formulaic language instruction and again after the 6-week training session. The results showed that she made a $13.8 \%$ gain (123.2 to 140.2) in speech rate with syllable per minute and a $26.3 \%$ (5.1 to 6.4) gain in mean length of runs with syllables per a run between the pretest and posttest. The workshop also improved her complexity, as she used a greater variety of formulaic language. Before the fluency workshop, she produced 18 tokens of formulaic language. After the workshop, she used 52 tokens of formulaic language. This result suggests that the fluency workshop provided the participant with samples of formulaic language, which she added to her repertoire; thus, her utterances became more fluent. Although Wood's study shows an interesting finding, it is quite difficult to generalize the result due to sample size.

To summarize, formulaic language is an important factor to help L2 speakers sound more fluent because automatic retrieval of prefabricated chunks is faster than retrieving word by word. The effects of teaching formulaic language showed that an L2 speaker improved speaking (Wood, 2009). Yet, it is difficult for L2 learners to master formulaic language partly because L2 learners have little exposure with formulaic language although they are common among native speakers' speech (Wray, 2000). Indeed, few studies have examined the effects of pedagogical intervention on specific target formulaic language on the L2 learners' speaking development as an experimental study. More studies are needed to focus on the formulaic language and speaking development.

\section{References}

Boers, F. (2014). A reappraisal of the 4/3/2 activity. RELC Journal, 45(3), 221-235. doi:10.1177/0033688214546964

Boers, F., Eyckmans, J., Kappel, J., Stengers, H., \& Demecheleer, M. (2006). Formulaic sequences and perceived oral proficiency: Putting a lexical approach to the test. Language Teaching Research, 10(3), 245-261. doi:10.1191/13621688061r195oa

Boers, F., \& Lindstromberg, S. (2012). Experimental and intervention studies on formulaic sequences in a second language. Annual Review of Applied Linguistics, 32, 83-110. doi:10.1017/S0267190512000050

Vocabulary Learning and Instruction, 9 (2), 48-54. 
De Jong, N., \& Perfetti, C. A. (2011). Fluency training in the ESL classroom: An experimental study of fluency development and proceduralization. Language Learning, 61(2), 533-568. doi:10.1111/j.1467-9922.2010.00620.x

DeKeyser, R. (2003). Implicit and explicit learning. In C. J. Doughty \& H. M. Long (Eds.), The handbook of second language acquisition (pp. 312-348). Oxford, England: Blackwell.

De Ridder, I., Vangehuchten, L., \& Gómez, M. (2007). Enhancing automaticity through task- based language learning. Applied Linguistics, 28(2), 309-315. doi:10.1093/applin/am1057

Doughty, C. (1991). Second language instruction does make a difference: Evidence from an empirical study of SL relativization. Studies in Second Language Acquisition, 13(4), 431-469.

Ellis, N. C. (1996). Sequencing in SLA: Phonological memory, chunking and points of order. Studies in Second Language Acquisition, 18, 91-126. doi:10.1017/ S0272263100014698

Ellis, R. (2016). Focus on form: A critical review. Language Teaching Research, 20(3), 405-428. doi:10.1177/1362168816628627

Gatbonton, E., \& Segalowitz, N. (1988). Creative automatization: Principles for promoting fluency within a communicative framework. TESOL Quarterly, 22(3), 473-492. doi:10.2307/3587290

Kim, Y. (2013). Effects of pretask modeling on attention to form and question development. TESOL Quarterly, 47(1), 8-35. doi:10.1002/tesq.52

Lee, S., \& Huang, H. (2008). Visual input enhancement and grammar learning: A meta-analytic review. Studies in Second Language Acquisition, 30(3), 307-331. doi:10.1017/S0272263108080479

Levelt, W. J. M. (1989). Speaking: From intention to articulation. Cambridge, MA: MIT Press.

Lyster, R., \& Saito, K. (2010). Oral feedback in classroom SLA: Meta-analysis. Studies in Second Language Acquisition, 32, 265-302. doi:10.1017/S0272263109990520

Mackey, A., \& Goo, J. (2007). Interaction research in SLA: A meta-analysis and research synthesis. In A. Mackey (Ed.), Conversational interaction in second language acquisition: A collection of empirical studies (pp. 407-452). Oxford, England: Oxford University Press.

Nation, I. S. P. (1989). Improving speaking fluency. System, 17(3), 377-384. doi:10.1016/0346-251X(89)90010-9

Nation, I. S. P., \& Newton, J. (2009). Teaching ESL/EFL listening and speaking. New York, NY: Routledge.

Ogawa, C. (2019). Low-proficiency university students' perceptions of pretask planning and their monologue task performances. In Proceedings of the TBLT in Asia 2018 Conference (pp. 16-25). Kyoto, Japan: JALT TBLT SIG.

Philp, J., Walter, S., \& Basturkmen, H. (2010). Peer interaction in the foreign language classroom: What factors foster a focus on form? Language Awareness, 19(4), 261-279. doi:10.1080/09658416.2010.516831 
Russell, J., \& Spada, N. (2006). The effectiveness of corrective feedback for second language acquisition: A meta-analysis of the research. In J. Norris \& L. Ortega (Eds.), Synthesizing research on language learning and teaching (pp. 133-164). Amsterdam, The Netherlands: Benjamins.

Sato, M. (2017). Oral peer corrective feedback: Multiple theoretical perspectives. In H. Nassaji \& E. Kartchava (Eds.), Corrective feedback in second language teaching and learning (pp. 19-34). New York, NY: Routledge.

Segalowitz, N. (2003). Automaticity and second languages. In C. J. Doughty \& M. H. Long (Eds.), The handbook of second language acquisition (pp. 382-408). Malden, MA: Blackwell.

Sharwood-Smith, M. (1993). Input enhancement in instructed SLA: Theoretical bases. Studies in Second Language Acquisition, 15(2), 165-179.

Sippel, L., \& Jackson, C. N. (2015). Teacher vs. peer oral corrective feedback in the German language classroom. Foreign Language Annals, 48(4), 688-705. doi:10.1111/flan.12164

Skehan, P. (1998). A cognitive approach to language learning. Oxford, England: Oxford University Press.

Thai, C., \& Boers, F. (2016). Repeating a monologue under increasing time pressure: Effects on fluency, complexity, and accuracy. TESOL Quarterly, 50(2), 369-393. doi:10.1002/tesq.232

Wood, D. (2009). Effects of focused instruction of formulaic sequences on fluent expression in second language narratives: A case study. Canadian Journal of Applied Linguistics, 12(1), 39-57. Retrieved from https://search-proquestcom.libproxy.temple.edu/docview/85716551?accountid=14270

Wood, D. (2010). Formulaic language and second language speech fluency. London, England: Continuum.

Wood, D. (2015). Fundamentals of formulaic language: An introduction. London, England: Bloomsbury.

Wray, A. (2000). Formulaic sequences in second language teaching: Principle and practice. Applied Linguistics, 21(4), 463-489. doi:10.1093/applin/21.4.463

Wray, A. (2002). Formulaic language and the lexicon. Cambridge, England: Cambridge University Press.

Wray, A. (2008). Formulaic language: Pushing the boundaries. Oxford, England: Oxford University Press.

Wray, A. (2013). Formulaic language. Language Teaching, 46(3), 316-334. doi:10.1017/ S0261444813000013 